\title{
Radiation Oncologist
}

National Cancer Institute

\section{Source}

National Cancer Institute. Radiation Oncologist. NCI Thesaurus. Code C17833.

A physician who specializes in the treatment of cancer patients, using radiation as the main modality of treatment. 